\title{
Biomimetic earthworm dynamic soil looser for improving soybean emergence rate in cold and arid regions
}

\author{
Jiale Zhao ${ }^{1,2}$, Xiaogeng Wang ${ }^{1,2}$, Yun $\mathrm{Lu}^{1,2}$, Yanpeng Wei ${ }^{1,2}$, Mingzhuo Guo ${ }^{1.2}$, Jun $\mathrm{Fu}^{1,2^{*}}$ \\ (1. College of Biological and Agricultural Engineering, Jilin University, Changchun 130025, China; \\ 2. Key Laboratory of Bionics Engineering, Ministry of Education, Jilin University, Changchun 130025, China)
}

\begin{abstract}
In cold and arid regions, soil moisture content and accumulated temperature were seriously insufficient during spring sowing, which made it difficult for soybean seedling to emerge. Based on the principle of earthworm optimization and improvement of soil structure, this study innovatively designed a biomimetic earthworm dynamic soil looser through bionic design and theoretical calculation. By highly reducing the movement path and mode of earthworm in the soil, the mechanism could improve the soil temperature (ST) and soil moisture content (SMC), and thus greatly improve the soybean emergence rate (SER). In this study, the effects of biomimetic earthworm dynamic soil looser and its design parameters on soil temperature (ST), soil moisture content (SMC) and soybean emergence rate (SER) were investigated by two-factor test, analysis of variance (ANOVA) and Least significant Difference (LSD). Regression analysis was used to establish the mathematical model between design parameters and soybean emergence rate. MATLAB software was used to optimize the model, and the optimal design parameter combination was obtained. The contrast experiments showed that the biomimetic earthworm dynamic soil looser could construct the soil structure more suitable for the cold and arid regions. Compared with rotary blade (RB) and notched disc harrow (DH), biomimetic earthworm dynamic soil looser could increase soil moisture content by $41.30 \%$ and $27.50 \%$, respectively. Compared with the notched disc harrow, the soil temperature could be increased by $7.97 \%$. There was no significant difference between the effect of rotary blade on soil temperature $(p>0.05)$. The soybean emergence rate was increased by $25.40 \%$ and $20.70 \%$, respectively, compared with that of notched disc harrow and rotary blade.
\end{abstract}

Keywords: bionics, earthworm, tillage, soil temperature, soil moisture content, soybean emergence rate

DOI: $10.25165 /$ j.ijabe.20211403.6326

Citation: Zhao J L, Wang X G, Lu Y, Wei Y P, Guo M Z, Fu J. Biomimetic earthworm dynamic soil looser for improving soybean emergence rate in cold and arid regions. Int J Agric \& Biol Eng, 2021; 14(3): 22-31.

\section{Introduction}

How to improve the soybean emergence rate in cold and arid regions has been one of the pressing problems in the agricultural field. Soybean, as a typical thermophilic and hydrophytic crop, can only be guaranteed under the condition of suitable soil temperature and moisture content ${ }^{[1,2]}$. The soil temperature and moisture content mainly depend on the climate characteristics and soil conditions of the planting are $\mathrm{a}^{[3]}$. Air temperature, solar radiation, atmospheric circulation and precipitation determine the environmental conditions of the soil ${ }^{[4]}$. Soil compactness and soil porosity determine the exchange rate of water and heat between soil and the environment ${ }^{[5]}$. Therefore, if a reasonable soil structure can be constructed according to the climate characteristics of the region, soil temperature and moisture content and other indicators can be significantly improved, and thus the soybean emergence rate can be increased.

Combined tillage and sowing can affect soil temperature and

Received date: 2020-12-04 Accepted date: 2021-04-22

Biographies: Jiale Zhao, PhD, Assistant Professor, research interests: conservation tillage, Email: zhaojiale0313@163.com; Xiaogeng Wang, MS, research interests: conservation tillage, Email: xgwang1998@163.com; Yun Lu, PhD candidate, research interests: conservation tillage, Email: 83603557@ 163.com; Yanpeng Wei, MS, research interests: conservation tillage, Email: 335212670@qq.com; Mingzhuo Guo, PhD, Lecturer, research interests: conservation tillage, Email: guomingzhuo@outlook.com.

*Corresponding author: Jun Fu, PhD, Professor, research interests: maize harvesting. Key Laboratory of Bionics Engineering, Ministry of Education, Jilin University, Changchun 130025, China. Tel: +86-13843122197, Email: fu_jun@jlu.edu.cn. moisture content during spring sowing by changing soil structure ${ }^{[6]}$. At present, there are two types of cultivator-planting combine. The first is the passive rotating tillage mechanism, which is typically represented as a notched disc harrow and operates in a low-speed rotation model. Although this kind of mechanism can loosen the soil, it cannot turn over the soil ${ }^{[7]}$. Therefore, the soil moisture lost less after the operation, but the soil temperature rose more slowly ${ }^{[8]}$. The second is the driving rotary tillage mechanism, which is typically represented by rotary tillage blade and operates in a high-speed rotation mode ${ }^{[9]}$. This kind of mechanism can turn the soil into the plough layer and greatly improve the soil porosity ${ }^{[10]}$. Therefore, although it will accelerate soil moisture loss, it can significantly improve soil temperature ${ }^{[11]}$. In conclusion, the notched disc harrow is suitable for planting areas with higher temperatures but less precipitation. A rotary blade is suitable for planting areas with low temperatures but sufficient precipitation.

Obviously, it is difficult for the existing tillage mechanism to increase the rate of soil heat absorption while reducing the rate of soil moisture loss. Therefore, the existing tillage mechanism is not suitable for cold and arid regions ${ }^{[12]}$. For example, the soybean emergence rate in the black earth area of northeast China has been at a low level for a long time ${ }^{[13]}$. In this region, the soil temperature is much lower than the air temperature during spring sowing. Therefore, it is necessary to accelerate the rate of heat exchange in order to improve the soil temperature rapidly. However, there is basically no rainfall during spring sowing in this region and the soil moisture content is completely dependent on internal storage and groundwater, so the rate of moisture loss should be reduced as far as possible ${ }^{[14,15]}$. Therefore, it is 
necessary to develop a new tillage mechanism that can increase the rate of heat absorption and reduce the rate of moisture loss simultaneously in order to improve the soybean emergence rate in cold and dry regions.

$\mathrm{Li}$ et al. ${ }^{[16]}$ found that the soil temperature and soil moisture content of the black earth area in northeast China where there are a large number of earthworms are much higher than in other areas. Bardgett et al. ${ }^{[17]}$ found that the improving function of earthworm on soil physical properties was due to its special movement path and mode. Earthworms need to move above the surface when foraging for food. After foraging for food, they will return to the soil to avoid predators, thus creating a large number of large pores that pass through from top to bottom. In general, soil porosity is directly proportional to heat absorption rate ${ }^{[18]}$. As the earthworm moves, its circular muscles expand periodically, thus, periodic flexible compaction of the soil is carried out while creating pores ${ }^{[19]}$. Compaction operations can significantly improve soil compactness and soil porosity, thereby slowing down moisture loss and enhancing the ability to absorb groundwater ${ }^{[20]}$. The unique movement path and movement mode of earthworms can provide a new design idea for the development of tillage mechanism suitable for cold and arid regions.

To sum up, this study designed a biomimetic tillage mechanism which can reproduce the excellent function of earthworm by using bionics. The effects of the key design parameters on soil temperature (ST), soil moisture content (SMC) and soybean emergence rate (SER) in the black earth area of northeast China were studied by two-factor comparative test. The mathematical model between the design parameters of biomimetic tillage mechanism and the soybean emergence rate was established, and the optimal design parameter combination was obtained through model optimization. This study can provide theoretical and equipment support for improving soil physical properties and soybean planting quality in the black earth area of northeast China.

\section{Design of biomimetic earthworm dynamic soil looser}

2.1 Overall structure and operation principle of the biomimetic earthworm dynamic soil looser

In order to reproduce the earthworm's ability to optimize and improve the physical properties of soil, the biomimetic earthworm dynamic soil looser needs to reproduce the movement mode and path of earthworms respectively. As shown in Figure 1, the biomimetic earthworm dynamic soil looser is mainly composed of bionic drive mechanism and bionic motion mechanism.
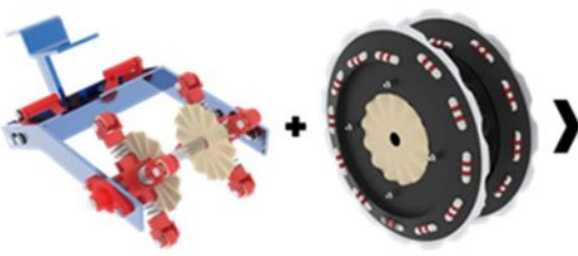

Bionic drive mechanism Bionic motion mechanism

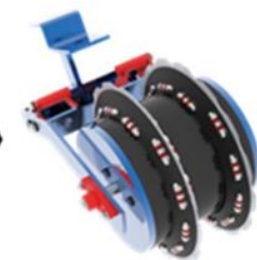

Biomimetic earthworm dynamic soil looser

Figure 1 Structure diagram of biomimetic earthworm dynamic soil looser

As shown in Figure 2a, the bionic drive mechanism is composed of two corrugated disks, two sets of profiling mechanisms and a rack. As shown in Figure $2 b$, the two corrugated disks are fixed with the rack respectively. When the earthworm dynamic soil looser is completely assembled, the corrugated disks are placed just between the two broken earth disks As shown in Figure 2c, each set of profiling mechanism is composed of four rolling shafts, which are arranged in a $90^{\circ}$ symmetric arrangement. The top of the rolling shaft is provided with a roller, and the spring under the roller is firmly connected with the main shaft. The rolling shaft can be shaped with the ridge during operation.

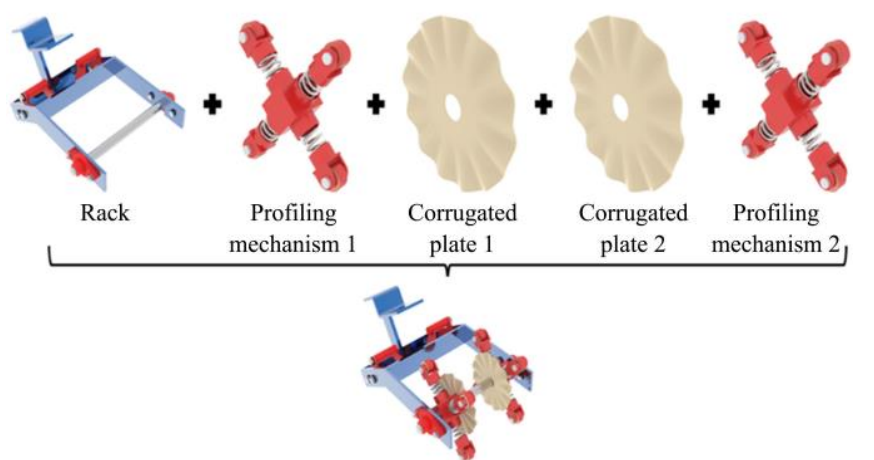

Bionic drive mechanism

a. Schematic diagram of bionic drive mechanism

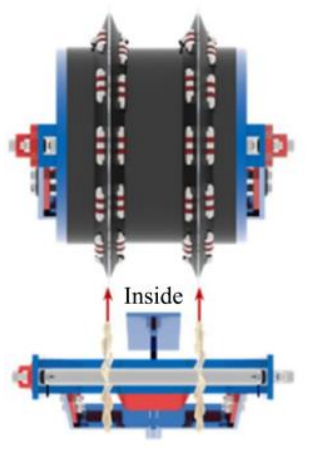

b. Schematic diagram of installation position of corrugated disk

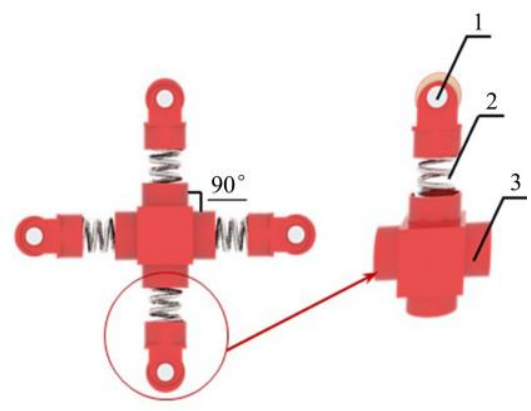

1. Roller 2. Spring 3. Main shaft c. Schematic diagram of profiling mechanism
Figure 2 Schematic diagram of bionic driving mechanism

As shown in Figure 3a, the biomimetic motion mechanism is composed of four broken earth disks, three sleeves, two retaining plates and four sets of biomimetic earthworm circular muscle mechanisms (twelve for each set). As shown in Figure 3b, each earthworm's circular muscle mechanism is composed of three rigid bulges, two flexible bulges, a connecting rod and a roller. The five bulges are interlaced in turn and then installed at the gap of the earth plate. The two flexible bulges are fixed to the roller through the connecting rod, which is installed in the circular grooved track of the corrugated disk. As shown in Figure 3c, Sleeves 1 and 3 are respectively composed of two semicircular sleeves, and the semicircular sleeve is provided with a circular grooved track. The bionic motion mechanism can rotate around the geometric center of the profiling mechanism by fitting the four rollers of the profiling mechanism into the circular grooved track inside the sleeve.

As shown in Figure 4, the driving mechanism (the rack and the corrugated disk) will shift forward without rotation during the ploughing and sowing machine operation. Under the action of soil resistance, four sets of earthworm circular muscle mechanism are driven to rotate simultaneously. With the relative rotation between the biomimetic motion mechanism and the drive mechanism, the earthworm circular mechanism roller rolls at high speed on the surface of the corrugated disc. When the roller moves from the trough on the corrugated disk surface to the crest, the two flexible bulges expand in the radial direction and drive the rigid bulges on both sides to contract in the axial direction at the 
same time. When the roller moves from the crest of the corrugated disk surface to the trough, the two flexible bulges contract in the radial direction and drive the rigid bulges on both sides to expand in the axial direction. Thus, with the undulation of the corrugated disk surface, the earthworm circular muscle can simulate the periodic expansion and contraction of the earthworm circular muscle, and then reproduce the flexible squeezing and loosening mode. With the advancement of the machines, four sets of earthworm circular muscle mechanisms have been continuously completed the earthworm entry and excavation work, and then the transversal movement path of earthworms has been reconstructed.
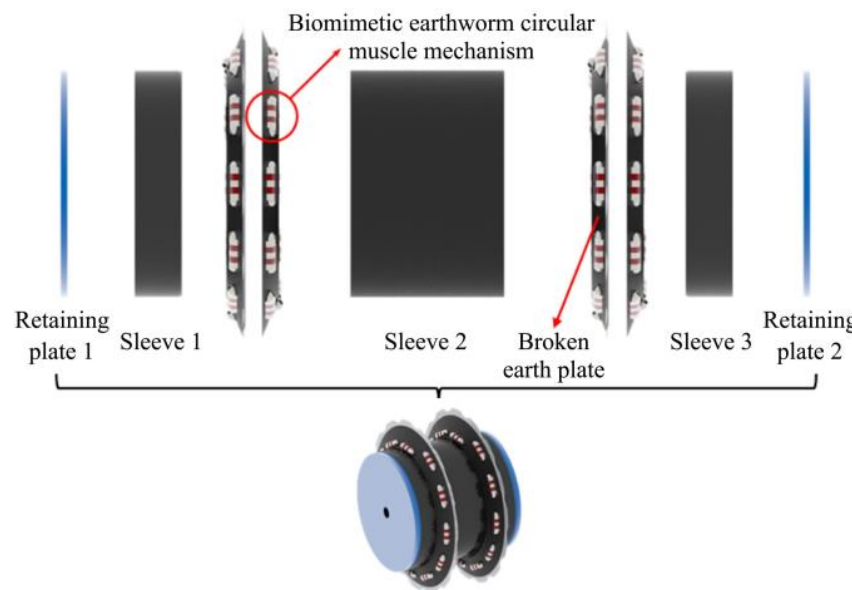

Bionic motion mechanism

a. Schematic diagram of biomimetic motion mechanism

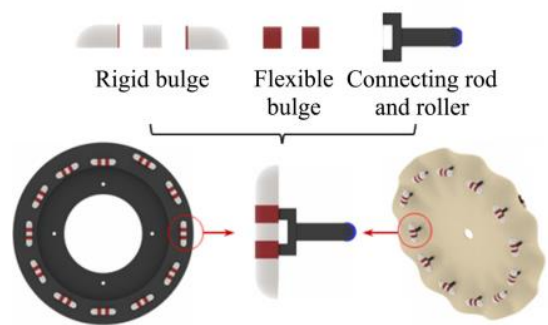

b. Schematic diagram of biomimetic earthworm circular muscle mechanism

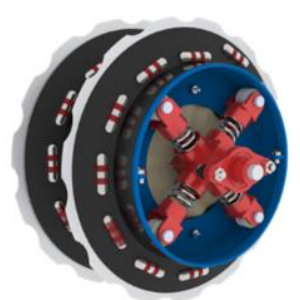

c. Matching diagram of motion mechanism and driving mechanism
Figure 3 Schematic diagram of bionic motion mechanism
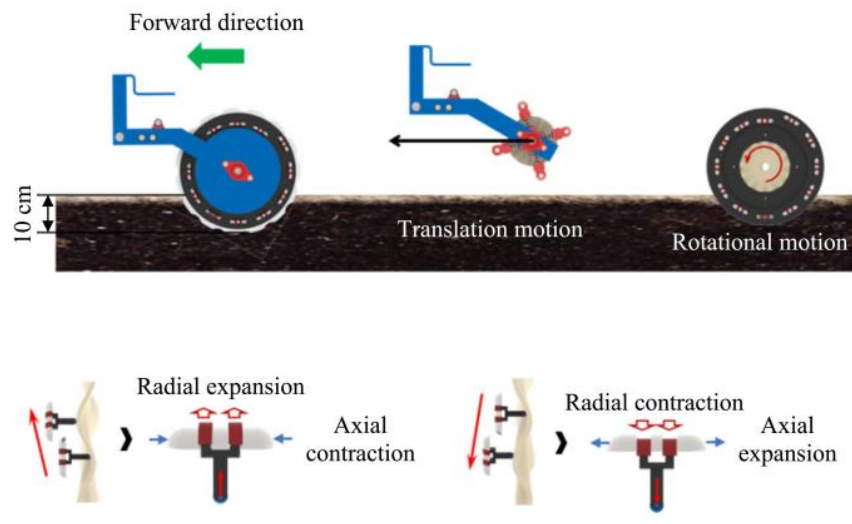

From the trough to the crest

From the crest to the though

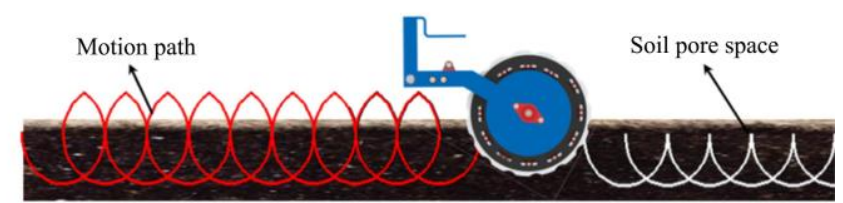

Figure 4 Working diagram of biomimetic earthworm dynamic soil looser

\subsection{Design of key components}

\subsubsection{Design of corrugated disk}

In order to further reduce the flexible extrusion pattern of earthworm, the earthworm circular muscle mechanism should have no rigid impact or flexible impact on the soil, that is, the velocity and acceleration of the earthworm circular muscle mechanism when the roller moves to the crest or trough of the corrugated disk should be 0 . Therefore, the roller should move with sinusoidal acceleration. Thus, the corrugated surface structure function of the corrugated disk can be expressed as Equation (1) ${ }^{[21]}$.

$$
\left\{\begin{array}{l}
Z=H\left[\left(x / x_{0}\right)-\frac{\sin \left(2 \pi x / x_{0}\right)}{2 \pi}\right]\left(0 \leq x<x_{0}\right) \\
Z=H\left[1-\left(x / x_{0}\right)+\frac{\sin \left(2 \pi x / x_{0}\right)}{2 \pi}\right]\left(x_{0} \leq x \leq x_{0}+x_{1}\right)
\end{array}\right.
$$

where, $x_{0}$ is the length of the trough to the crest, $\mathrm{m} ; x_{1}$ is the length of the crest to the trough, $\mathrm{m} ; H$ is the height of bump, $\mathrm{m}$.

The diameter of the corrugated disc should be slightly smaller than the diameter of the broken earth disc. A large number of studies have shown that when the diameter of the broken earth disc is $270 \mathrm{~mm}$, the earth breaking operation effect is the best Therefore, the corrugated disk diameter is set to $250 \mathrm{~mm}$. Thus, the contour curve equation of the corrugated disk is obtained as Equation $(2)^{[21]}$.

$$
\left\{\begin{array}{l}
Z=H\left[\left(x / 125 \sin \frac{\pi}{N}\right)-\frac{\sin \left(2 \pi x / 125 \sin \frac{\pi}{N}\right)}{2 \pi}\right]\left(0 \leq x<125 \sin \frac{\pi}{N}\right) \\
Z=H\left[1-\left(x / 125 \sin \frac{\pi}{N}\right)+\frac{\sin \left(2 \pi x / 125 \sin \frac{\pi}{N}\right)}{2 \pi}\right] \\
\left(125 \sin \frac{\pi}{N} \leq x \leq 250 \sin \frac{\pi}{N}\right)
\end{array}\right.
$$

where, $N$ is the number of crests in a corrugated disk.

2.2.2 Distribution curve design of biomimetic earthworm circular muscle mechanism

In order to further reduce the transversal movement path of earthworms and reduce the working resistance, the movement track of each set of earthworm circular muscle mechanism should be basically identical. Therefore, the twelve earthworm circular muscles in each group should be arranged in a spiral of Archimedes and spaced at $30^{\circ}$ intervals. In order to ensure that all biomimetic earthworm circular mechanisms can be put into the soil for operation, the first earthworm circular mechanism can be placed $100 \mathrm{~mm}$ away from the axis of the outer disk when the spiral of Archimedes is rotated by $630^{\circ}$. When the spiral of Archimedes turns $990^{\circ}$, it is $120 \mathrm{~mm}$ from the axis of the outer disk. Thus, the polar coordinate equation of the distribution curve of each group of earthworm circular muscle mechanism is

$$
\left\{\begin{array}{l}
x=\left(65+\frac{10}{\pi} \theta\right) \cos \theta \\
y=\left(65+\frac{10}{\pi} \theta\right) \sin \theta
\end{array}\left(\frac{7}{2} \pi \leq \theta \leq \frac{16}{3} \theta\right)\right.
$$




\section{Materials and methods}

\subsection{Site description and test time}

The test site is the teaching and research base of Jilin University $\left(43^{\circ} 55^{\prime} 0.26^{\prime \prime} \mathrm{N}, 125^{\circ} 16^{\prime} 8.36^{\prime \prime} \mathrm{E}\right)$, located in Changchun, Jilin, China, the climate conditions belong to the temperate monsoon climate, high temperature and rainy in summer, cold and dry in winter, the soil type is black clay. The selected soybean variety was Hefeng50, and the planting mode was double row interlacing on ridge. The main physical properties of soil are shown in Table 1. The soil temperature was measured by an 11000 Temperature Gauge (Midwest Company, USA). The soil moisture content was measured by the MS-350 Soil Moisture Content Tester (Spectrum Company, USA). The soil compactness was measured by the SC-900 Soil Compactness Tester (Spectrum Company, USA). The $\mathrm{pH}$ value was measured by the CT-8022 pH meter (Qingdao Lubo Company, China). The instrument and sampling process are shown in Figure 5.

Table 1 Physical parameters of soil in test sites before tests

\begin{tabular}{lc}
\multicolumn{1}{c}{ Parameter } & Values \\
\hline Soil type & Black clay \\
Soil compactness/MPa & 0.40 \\
Soil temperature $/{ }^{\circ} \mathrm{C}$ & 12.20 \\
Soil moisture content $/ \%$ & 12.60 \\
pH value & 7.08 \\
Soil volume density $/ \mathrm{g} \cdot \mathrm{cm}^{-3}$ & 1.33
\end{tabular}

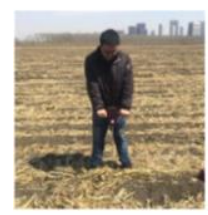

a.

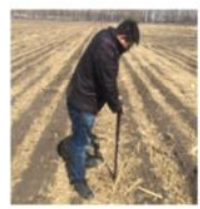

e.

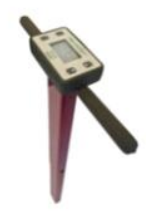

b.

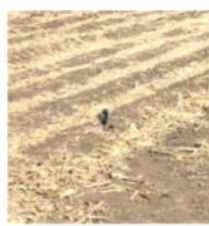

c.

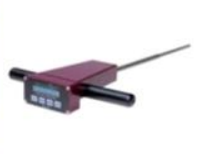

f.
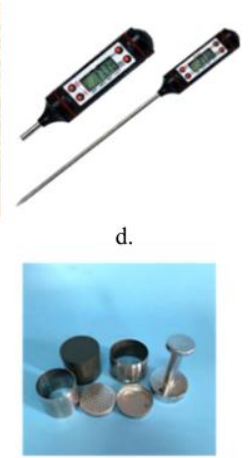

h.
Note: a. Soil moisture content field indicator measurement; b. MS-350 moisture meter (Spectrum USA); c. Soil temperature field indicator measurement; d. 11000 Temperature Gauge (Midwest company USA); e. Soil Compactness field indicator measurement; f. SC-900 Soil Compactness Tester (Spectrum USA); g. CT-8022 pH meter (Qingdao Lubo company, China); h. Cutting Ring.

Figure 5 Schematic diagram of test instrument and sampling

$$
\text { process of soil condition testing }
$$

\subsection{Test design and methods}

The working effect of tillage components mainly depends on the disturbance intensity and frequency to the soil. According to Equation (4), the bump height $(H)$ of the biomimetic earthworm circular muscle mechanism determines the squeezing extent of the soil, and the number of crests in a corrugated disk $(N)$ determines the squeezing frequency of the soil. Therefore, $H$ and $N$ were selected as the experimental factors for the two-factor multi-level comparison test, and the notched disc harrow (DH) and rotary blade (RB) were set as the comparison group.

$$
\left\{\begin{array}{l}
T=\frac{2 \pi}{\omega N} \\
V=\omega R_{2} \\
f=\frac{1}{T}
\end{array} \rightarrow f=\frac{V N}{2 \pi R_{2}}\right.
$$

The ploughing and sowing time is May 1, 2020. Before the experiment, the experimental site was divided into eleven blocks, each block was six ridges wide and $190 \mathrm{~m}$ long (Each ridge was $650 \mathrm{~mm}$ wide and $180 \mathrm{~mm}$ high). Each block was divided into four plots, each block and its responding factor combination is shown in Figure 6. Since the effective emergence period of soybean in the black soil area of northeast China is $15 \mathrm{~d}$, the experimental data collection time is from May 1 to May 15, 2020. Each treatment combination of the statistics is listed in Table 2.

Table 2 Summary of statistical analysis of the respective

\begin{tabular}{|c|c|c|c|c|c|}
\hline \multirow{2}{*}{$\begin{array}{l}\text { Factor } \\
(H \times N)\end{array}$} & \multicolumn{5}{|c|}{ Variable } \\
\hline & $\mathrm{SMC} / \%$ & $\mathrm{ST} /{ }^{\circ} \mathrm{C}$ & $\mathrm{SP} / \%$ & $\mathrm{SC} / \mathrm{MPa}$ & SER/\% \\
\hline $4 \times 12$ & $17.4^{\mathrm{a}}$ & $15.8^{\mathrm{a}}$ & $41.2^{\mathrm{a}}$ & $0.74^{\mathrm{a}}$ & $83.2^{\mathrm{a}}$ \\
\hline $4 \times 15$ & $18.4^{\mathrm{b}}$ & $16.6^{\mathrm{b}}$ & $42.3^{\mathrm{b}}$ & $0.84^{\mathrm{b}}$ & $87.1^{\mathrm{b}}$ \\
\hline $4 \times 18$ & $17.0^{\mathrm{c}}$ & $17.5^{\mathrm{c}}$ & $43.3^{\mathrm{c}}$ & $0.71^{\mathrm{c}}$ & $81.9^{c}$ \\
\hline $4 \times 20$ & $16.5^{\mathrm{d}}$ & $18.2^{\mathrm{d}}$ & $44.5^{\mathrm{d}}$ & $0.67^{\mathrm{d}}$ & $80.5^{\mathrm{d}}$ \\
\hline $7 \times 12$ & $18.7^{\mathrm{a}}$ & $16.7^{\mathrm{a}}$ & $42.6^{\mathrm{a}}$ & $0.88^{\mathrm{a}}$ & $88.1^{\mathrm{a}}$ \\
\hline $7 \times 15$ & $19.6^{\mathrm{b}}$ & $17.4^{\mathrm{b}}$ & $44.1^{\mathrm{b}}$ & $0.97^{\mathrm{b}}$ & $91.8^{\mathrm{b}}$ \\
\hline $7 \times 18$ & $18.4^{\mathrm{c}}$ & $18.2^{\mathrm{c}}$ & $45.1^{\mathrm{c}}$ & $0.85^{\mathrm{c}}$ & $86.8^{\mathrm{c}}$ \\
\hline $7 \times 20$ & $17.6^{\mathrm{d}}$ & $18.8^{\mathrm{d}}$ & $46.2^{\mathrm{d}}$ & $0.79^{\mathrm{d}}$ & $85.0^{\mathrm{d}}$ \\
\hline $10 \times 12$ & $18.0^{\mathrm{a}}$ & $17.3^{\mathrm{a}}$ & $43.9^{\mathrm{a}}$ & $0.80^{\mathrm{a}}$ & $85.2^{\mathrm{a}}$ \\
\hline $10 \times 15$ & $19.0^{\mathrm{b}}$ & $17.9^{\mathrm{b}}$ & $45.6^{\mathrm{b}}$ & $0.91^{\mathrm{b}}$ & $89.5^{\mathrm{b}}$ \\
\hline $10 \times 18$ & $17.6^{\mathrm{c}}$ & $18.7^{\mathrm{c}}$ & $47.0^{\mathrm{c}}$ & $0.76^{\mathrm{c}}$ & $84.0^{\mathrm{c}}$ \\
\hline $10 \times 20$ & $17.1^{\mathrm{d}}$ & $19.2^{\mathrm{d}}$ & $48.4^{\mathrm{d}}$ & $0.71^{\mathrm{d}}$ & $82.2^{\mathrm{d}}$ \\
\hline $12 \times 12$ & $17.1^{\mathrm{a}}$ & $18.1^{\mathrm{a}}$ & $44.4^{\mathrm{a}}$ & $0.70^{\mathrm{a}}$ & $81.5^{\mathrm{a}}$ \\
\hline $12 \times 15$ & $17.8^{\mathrm{b}}$ & $18.6^{\mathrm{b}}$ & $46.0^{\mathrm{b}}$ & $0.80^{\mathrm{b}}$ & $85.5^{\mathrm{b}}$ \\
\hline $12 \times 18$ & $16.5^{\mathrm{c}}$ & $19.5^{\mathrm{e}}$ & $47.4^{\mathrm{c}}$ & $0.68^{\mathrm{c}}$ & $79.8^{\mathrm{c}}$ \\
\hline $12 \times 20$ & $16.1^{\mathrm{d}}$ & $19.6^{\mathrm{e}}$ & $48.9^{\mathrm{d}}$ & $0.63^{\mathrm{d}}$ & $78.1^{\mathrm{d}}$ \\
\hline \multicolumn{6}{|c|}{ Control group } \\
\hline$L_{1}(\mathrm{RB})$ & $13.8^{\mathrm{e}}$ & $19.7^{\mathrm{e}}$ & $51.2^{\mathrm{e}}$ & $0.45^{\mathrm{e}}$ & $74.3^{\mathrm{e}}$ \\
\hline$L_{2}(\mathrm{DH})$ & $15.3^{\mathrm{f}}$ & $16.3^{\mathrm{f}}$ & $39.5^{\mathrm{f}}$ & $0.58^{\mathrm{f}}$ & $77.2^{\mathrm{f}}$ \\
\hline \multicolumn{6}{|c|}{$F$-Test } \\
\hline$F_{1}(\mathrm{H})$ & $890.254^{*}$ & $3820.73^{*}$ & $5242.90^{*}$ & $1092.76^{*}$ & $13183.94^{*}$ \\
\hline$F_{2}(\mathrm{~N})$ & $752.153^{*}$ & $4412.77^{*}$ & $5686.91^{*}$ & $1027.92^{*}$ & $13463.11^{*}$ \\
\hline$F_{1} \times F_{2}$ & $2.675^{*}$ & $40.398^{*}$ & $33.692^{*}$ & $2.552^{*}$ & $24.5126^{*}$ \\
\hline
\end{tabular}
average and the results of $F$-test

Note: Soil moisture content (SMC), soil temperature (ST), soil porosity (SP), soil compactness (SC). Averages followed by the same letter in the column do not differ significantly by Tukey's test $(p<0.05)$. *: Significant at $5 \%$ probability $(p<0.05) . \quad L_{1}$ means the specific test value of the rotary blade as a control group $L_{2}$ means the specific test value of the notched disc harrow as a control group. $F_{1}$ means the specific value of the F-test for bump height $(\mathrm{H}) . \quad F_{2}$ means the specific value of the F-test for number of crests in a corrugated disk (N).

The research objective of this study is to reveal the influence rule of biomimetic earthworm dynamic soil looser on soil temperature $(S T)$ and soil moisture content $(S M C)$, and then to optimize the design parameter combination that can construct the optimal soil physical properties, so as to greatly improve the emergence rate of soybean in cold and arid regions. Therefore, while the above, soybean emergence rate (SER), soil temperature $(S T)$ and soil moisture content $(S M C)$ are selected as the test indexes, the change value of soil firmness $(S C)$ and the change value of soil porosity $(S P)$ before and after the operation are selected as the auxiliary analysis indexes. The change value of soil compactness can directly reflect the disturbance extent of tillage components to soil. Soil macropores are the main channels for heat exchange between soil and the environment, so soil porosity can reflect the capacity of soil to absorb heat. The test methods for the test indicators are as follows:

(1) Soil moisture content $(0-200 \mathrm{~mm})$

SMC was measured for 15 consecutive days after sowing. 
Five random points were sampled on the diagonal of each test plot. The average SMC with a depth of 0-200 $\mathrm{mm}$ was determined at each measurement point using the MS-350 moisture meter (Spectrum company, USA, resolution: $0.1 \%$ VWC, accuracy: $0.3 \%$ $(E C<2 \mathrm{mS} / \mathrm{cm})$, range: $0-50 \%$, power: 4 AA batteries, data capacity: 50000 GPS data). This was repeated three times and the average value was taken as the average SMC at this point. The mean value of 300 points was calculated by Equations (5) and (6) as the average SMC and variance of $0-200 \mathrm{~mm}$ in the test plot $^{[22]}$.

$$
\begin{gathered}
\overline{M_{S_{n t}}}=\sum_{i=1}^{15} \sum_{j=1}^{5} \sum_{k=1}^{4} \frac{M_{S_{n i j k}}}{300} \\
M_{S_{n t}}{ }^{\prime}=\sqrt{\sum_{i=1}^{15} \frac{\left(\sum_{j=1}^{5} \sum_{k=1}^{4} \frac{M_{S_{n i j k}}}{15}-\overline{M_{S_{n t}}}\right)^{2}}{15}}
\end{gathered}
$$

where, $\overline{M_{S_{n t}}}$ is the average SMC in the $S_{n t}, \% ; M_{S_{n t}}{ }^{\prime}$ is the standard deviation of SMC in the $S_{n t}, \% ; M_{S_{n t i j k}}$ is the $j$-th point value of the $i$-th test in the $S_{n t}, \% ; S_{n t}$ is the $k$-th plot in the test site (Figure 6).

(2) Soil temperature $(0-200 \mathrm{~mm})$

ST was measured for 15 consecutive days after sowing. Five random points were sampled on the diagonal of each test plot. The average ST with a depth of 0-200 $\mathrm{mm}$ was determined at each measurement point using the 11000 Temperature Gauge (Midwest company USA range: $-40^{\circ} \mathrm{C}-150^{\circ} \mathrm{C}$, accuracy: $\pm 0.5^{\circ} \mathrm{C}$, resolution: $0.1^{\circ} \mathrm{C}$, battery: $1.5 \mathrm{~V}$ button battery). This was repeated three times and the average value was taken as the average ST at this point. The mean value of 300 points was calculated by Equations (7) and (8) as the average $S M C$ and variance of $0-200 \mathrm{~mm}$ in the test plot $^{[22]}$.

$$
\begin{gathered}
\overline{T_{S_{n t}}}=\sum_{i=1}^{15} \sum_{j=1}^{5} \sum_{k=1}^{4} \frac{T_{S_{n i j k}}}{300} \\
T_{S n t}{ }^{\prime}=\sqrt{\sum_{i=1}^{15} \frac{\left(\sum_{j=1}^{5} \sum_{k=1}^{4} \frac{T_{S_{n i j k}}}{20}-\overline{T_{S n t}}\right)^{2}}{15}}
\end{gathered}
$$

where, $\overline{T_{S_{n t}}}$ is the average ST in the $T_{n t}, \% ; T_{S_{n t}}{ }^{\prime}$ is the standard deviation of ST in the $S_{n t}, \% ; T_{S_{n i j k}}$ is the $j$-th point value of the $i$-th test point in the $S_{n t}, \% ; S_{n t}$ is the $k$-th plot in the test site (Figure 6).

(3) Soybean emergence rate

The seedling emergence time of soybean in northeast black earth area of China is not more than $15 \mathrm{~d}$, so the soybean emergence rate is detected $15 \mathrm{~d}$ after sowing. In the tests, the planter was driven by a tractor, John Deere1204, and operated at $6-8 \mathrm{~km} / \mathrm{h}$, a common tillage method used to sow soybeans in the area $^{[23]}$. The planter seeded each plot four times, equivalent to dividing each plot into four parts. The number of missed seeding prompted by the alarm device was recorded after each seeding. Therefore, after $15 \mathrm{~d}$ of sowing, the number of seedlings in each part was checked, and the emergence rate of each part was calculated according to Equation $(9)^{[24]}$. The mean value and standard deviation of corresponding soybean emergence rate are shown in Equations (10) and (11) ${ }^{[24]}$.

$$
E_{S_{n k i}}=\frac{N_{S_{n k i}}}{\frac{30}{L} \times 6} \times 100 \%
$$

where, $N_{S_{n k i}}$ is the number of emergences after the $i$-th operation of the planter in Zone $S_{n k} ; L$ is the soybean plant spacing, $\mathrm{m}$. The length of the test area was $30 \mathrm{~m}$. The number of ridges was 6 . $S_{n k}$ is the $k$-th plot in the $n$-th block in the test site (Figure 6).

$$
\begin{gathered}
\overline{E_{S_{n k}}}=\sum_{i=1}^{4} \frac{E_{S_{n k i}}}{4} \\
E_{S_{n k}}{ }^{\prime}=\sqrt{\sum_{i=1}^{4} \frac{\left(E_{S_{n k i}}-E_{S_{n k}}\right)^{2}}{4}}
\end{gathered}
$$

where, $\overline{E_{S_{n k}}}$ is the average SER in the $S_{n k}, \% ; E_{S_{n k}}{ }^{\prime}$ is the standard deviation of SER in the $S_{n k}, \% ; E_{S_{n k i}}$ is the SER after the $i$-th operation of the planter in the $S_{n k}, \% ; S_{n k}$ is the $k$-th plot in the $n$-th block in the test site (Figure 6).

(4) Soil compactness

According to the national standard of the People's Republic of China (GB 7843-1987), the SC should be measured on the 15th day after sowing. As shown in Figure 6, five points were randomly selected on the diagonal line of each plot, and the SC of each point at a depth of $200 \mathrm{~mm}$ depth was detected by the SC-900SC detector (Spectrum company USA range: 0-450 $\mathrm{mm}$, pressure range: 0$2 \mathrm{MPa}$, accuracy: 0.01 MPa, conical head diameter: $12.827 \mathrm{~mm}$, power: 4AA batteries). Each point was detected three times, and the average value is obtained from twenty measured values, which was used as the SC of the corresponding plot. Then, the average value and standard deviation of SC of the corresponding plots were determined as follows:

$$
\begin{gathered}
\overline{C_{S_{n k}}}=\sum_{i=1}^{5} \frac{\sum_{j=1}^{4} \frac{C_{S_{n k i j}}}{4}=\sum_{i=1}^{5} \sum_{j=1}^{4} \frac{C_{S_{n k i j}}}{20}}{C_{S n t}{ }^{\prime}=\sqrt{\sum_{i=1}^{5} \frac{\left(\sum_{j=1}^{4} \frac{C_{S_{n i j}}}{4}-\overline{C_{S n t}}\right)^{2}}{5}}}
\end{gathered}
$$

where, $C_{S_{n k}}{ }^{\prime}$ is the average $\mathrm{SC}$ in the $S_{n k}, \mathrm{MPa} ; C_{S_{n k}{ }^{\prime}}$ is the standard deviation of $\mathrm{SC}$ in the $S_{n k}, \mathrm{MPa} ; C_{S_{n k j}}$ is the $j$-th measurement value of the $i$-th test point in the $S_{n k}, \mathrm{MPa} ; S_{n k}$ is the $k$-th plot in the $n$-th block in the test site (Figure 6).

(5) Soil porosity

SP was measured after combined tillage and sowing, five points were randomly sampled on the diagonal of each experimental plot, and the soil was weighed and repeated three times. After weighing, the saturated weight $W_{1}$ was obtained, which was then dried in an oven at $105^{\circ} \mathrm{C}$ to a constant weight, and the dry weight $W_{2}$ was obtained. The volume of the ring cutter was recorded as $100 \mathrm{~cm}^{3}$, SP was calculated, and the average value was taken as the $\mathrm{SP}$ at this point. The mean value of SP is calculated by Equations (14)-(16) as the SP and variance of the test plot.

$$
\begin{gathered}
S P=\frac{W_{1}-W_{2}}{100} \times 100 \% \\
\overline{M_{S_{S P}}}=\sum_{i=1}^{15} \sum_{j=1}^{5} \sum_{k=1}^{4} \frac{M_{S_{n k i j}}}{300} \\
M_{S_{S P}}{ }^{\prime}=\sqrt{\sum_{i=1}^{15} \frac{\left(\sum_{j=1}^{5} \sum_{k=1}^{4} \frac{M_{S_{n k j}}}{20}-\overline{M_{S_{S P}}}\right)^{2}}{15}}
\end{gathered}
$$

where, $\overline{M_{S_{S P}}}$ is the average SP in the $S_{n k}, \% ; E_{S_{n k}}{ }^{\prime}$ is the standard deviation of SP in the $S_{n k}, \% ; M_{S_{n k j}}$ is the SP after the $i$-th operation of the planter in the $S_{n k}, \% ; S_{n k}$ is the $k$-th plot in the $n$-th block in the test site (Figure 6). 


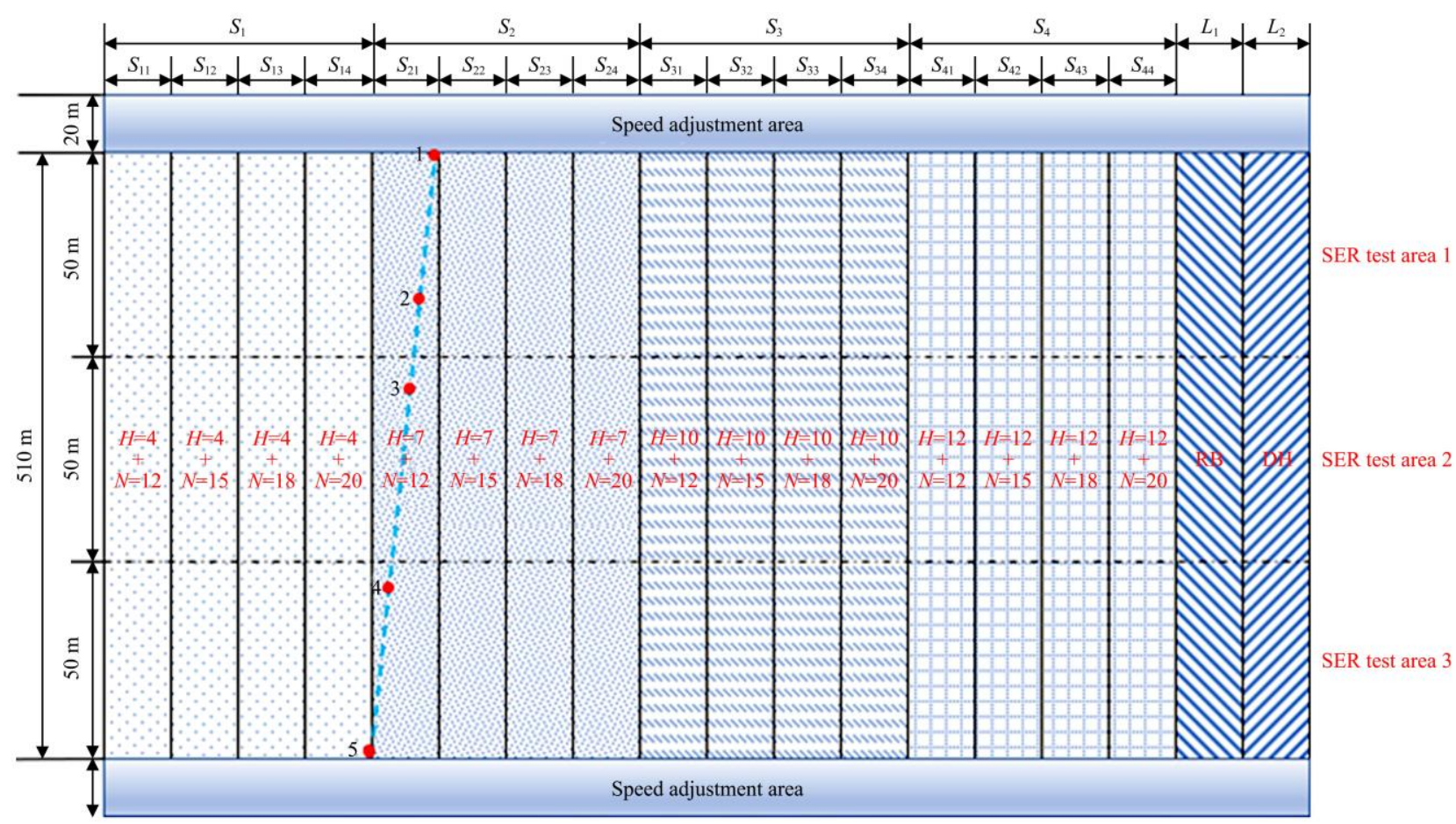

Note: Taking test site $S_{1}$ as an example, bump height $(H)$ level was chosen for each block, such as $H=4$ in test block $S_{1}$. Each block is divided into four plots. Each test plot corresponds to a combination of test factors. For example, test plot $S_{11}$ corresponds to the combination of " $H=4$ and $N=12$ ". Point selection: Schematic diagram of the test plot used for detecting the soil moisture content (SMC), soil temperature (ST), and soil compactness (SC). As shown in the figure, five points were randomly taken on the diagonal of each plot.

Figure 6 Corresponding distribution map of each test plot and its factor combination

\subsection{Statistical analyses}

Analysis of variance (ANOVA), Least Significant Difference (LSD), regression analysis, and Goodness of Fit (GOF) were used in this study to analyze the statistical data. ANOVA was used to analyze the variance of the obtained data and determine whether the test factors significantly impacted the test indicators. LSD was mainly used to determine whether there were significant differences among the different levels of one test factor and to compare the averages of different levels. The regression analysis was used to build regression models and find theoretical optimal values. The fitness and the significance of the regression equation were tested by the GOF and ANOVA, respectively.

\section{Results and discussion}

The analysis of variance (ANOVA) results of the variables with the respective average values and the results of $F$-tests are shown in Table 2. The results of $F$-tests shown in Table 2 were used to determine whether the test factors (SC and SP) have significant effects on the test indicators (SMC, ST, and SER). The test factors all had significant effects on the test indicators, and there was an interaction between each two test factors.

\subsection{Effect of biomimetic earthworm dynamic soil looser on SMC}

Figure 7 and AVONA results showed that the design parameters $(H$ and $N$ ) of biomimetic earthworm dynamic soil looser have significantly affected the SMC. LSD's analysis showed that SMC first increased and then decreased with $H$ and $N$. According to Equation (4), $H$ is proportional to the disturbance intensity, and $\mathrm{N}$ is proportional to the disturbance frequency. The results show that SMC increases first and then decreases with the enhancement of soil disturbance intensity and frequency by biomimetic earthworm dynamic soil looser. The research of Liang and Wang et al. ${ }^{[25,26]}$ showed that when the notched disc harrow and rotary blade were used, the SMC would decrease continuously with the increase of disturbance intensity and frequency. It can be seen from Figure 7 that the SMC of biomimetic earthworm dynamic soil looser is significantly higher than that of traditional tillage mechanism. When $H=7, N=15$, SMC could reach $19.6 \%, 42.0 \%$ and $28.1 \%$ higher than the rotary blade and notched disc harrow, respectively. In conclusion, the influence rule of biomimetic earthworm dynamic soil looser on $S M C$ is significantly different from that of traditional tillage mechanism, and it can significantly reduce soil moisture loss rate.

Figure 9, Figure 10 and AVONA results showed that the design parameters $(H$ and $N$ ) of biomimetic earthworm dynamic soil looser have significantly affected the SC and SP. LSD's analysis showed that SC first increased and then decreased with $H$ and $N$. The stronger the effect of tillage mechanism on soil looseness, the higher the SP value, the better the effect of the soil compaction, and the higher the SC value ${ }^{[27]}$. These results indicate that the biomimetic earthworm dynamic soil looser has three characteristics for soil tillage: (1) Biomimetic earthworm dynamic soil looser can loose and compact the soil at the same time; (2) When $H$ and $N$ are small, the compaction effect is greater than the loosening effect; (3) Both effects will increase with the increase of $\mathrm{H}$ and $\mathrm{N}$, and the increase rate of the loosing effect is faster. These three characteristics are due to the periodic expansion of the earthworm annulus muscle, which has both the effect of looseness and the effect of flexible compaction. The rotary forward motion of traditional tillage mechanism can only loose the soil. Figure 9 shows that the SC of earthworm dynamic soil looser was always higher than that of notched disc harrow and rotary blade. It can be seen that the difference in SC values is caused by the different motion modes of tillage. Figure 7 and Figure 9 show that when $H$ and $N$ are taken as different values, the variation trends of $S M C$ and SC are almost identical. When $H=7, N=15, S M C$ and $S C$ get the maximum value simultaneously. It can be seen that the soil moisture loss rate after tillage is inversely proportional to that of SC. In conclusion, the motion mode of biomimetic earthworm 
circular muscle is the main reason why biomimetic earthworm dynamic soil looser can significantly reduce the rate of soil moisture loss, and the influence law of biomimetic earthworm on SWC is different from traditional tillage mechanism. In conclusion, the motion mode of biomimetic earthworm circular muscle is the main reason why biomimetic earthworm dynamic soil looser can significantly reduce the rate of soil moisture loss, and the influence rule of SMC is different from that of traditional tillage mechanism.

4.2 Effect of biomimetic earthworm dynamic soil looser on ST

Figure 8 and AVONA results showed that the design parameters $(H$ and $N$ ) of biomimetic earthworm dynamic soil looser have significantly affected the ST. The analysis of LSD showed that ST always rises with the increase of $H$ and $N$, and the rising trend gradually slows down. It can be seen from Figure 8 that the ST value of the biomimetic earthworm dynamic soil looser was significantly higher than that of the notched disc harrow ( $p<0.05$ ). When $H=12, N=18$ or $N=20$, there was no significant difference in ST between earthworm dynamic soil looser and rotary blade, and in other cases, it was significantly lower than rotary blade. In conclusion, compared with the notched disc harrow, the biomimetic earthworm dynamic soil looser can significantly improve the ST. Only when the disturbance intensity and frequency of biomimetic earthworm dynamic soil looser are higher, its effect on ST enhancement is not significantly different from that of rotary blade.

Figure 9, Figure 10 and the ANOVA results showed that $H$ and $N$ significantly affected the SC and SP. LSD's analysis showed

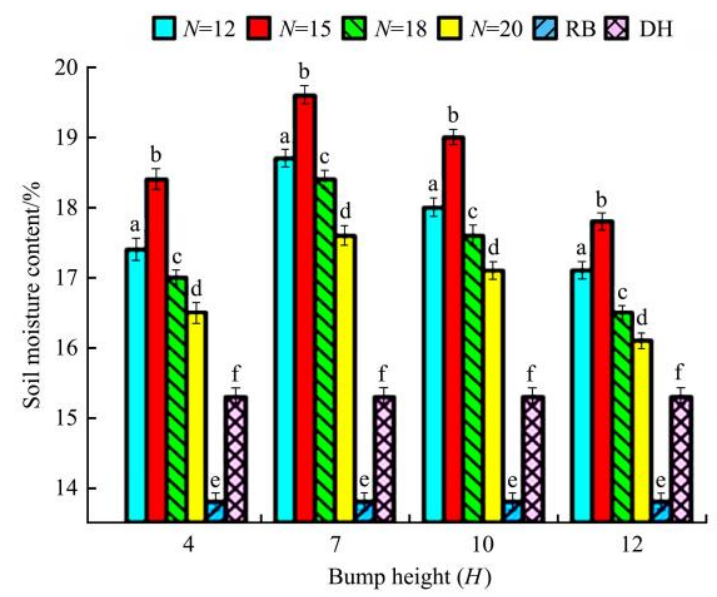

that SC first increased and then decreased with $H$ and $N$. The results showed that the ST enhancement effect of earthworm dynamic soil looser was not inversely proportional to the SC after operation, nor was it completely proportional to SP. The research of Feng et al. ${ }^{[28]}$ and Cong et al. ${ }^{[29]}$ showed that the use of notched disc harrow and rotary blade would cause SC to drop and SP to rise, thus accelerating the heat absorption rate of soil. Therefore, ST after traditional tillage mechanism operation is inversely proportional to $\mathrm{SC}$, and directly proportional to $\mathrm{SP}^{[30]}$. It can be seen that the biomimetic earthworm dynamic soil looser can improve the soil heat absorption rate in different ways from the traditional tillage parts. Besides SC and SP, the heat exchange rate between soil and environment is mainly affected by soil pore structure $^{[31]}$.

By simulating the motion path of earthworms, biomimetic earthworm dynamic soil looser can construct a large number of penetrating pores. At the same time, the biomimetic earthworm motion mode can realize the lateral extrusion of the soil around the pores, making the pores more solid. Figure 9 shows that the SC and ST of the biomimetic earthworm dynamic soil looser are always larger than the notch disc harrow. Figure 10 shows that SP of biomimetic earthworm dynamic soil looser is always significantly lower than that of rotary blade, but in some cases, there is no significant difference in ST. In conclusion, compared with the traditional tillage mechanism, the earthworm dynamic soil looser constructs a unique pore structure by simulating the movement mode and movement path of earthworms, which has a better effect on the improvement of ST.

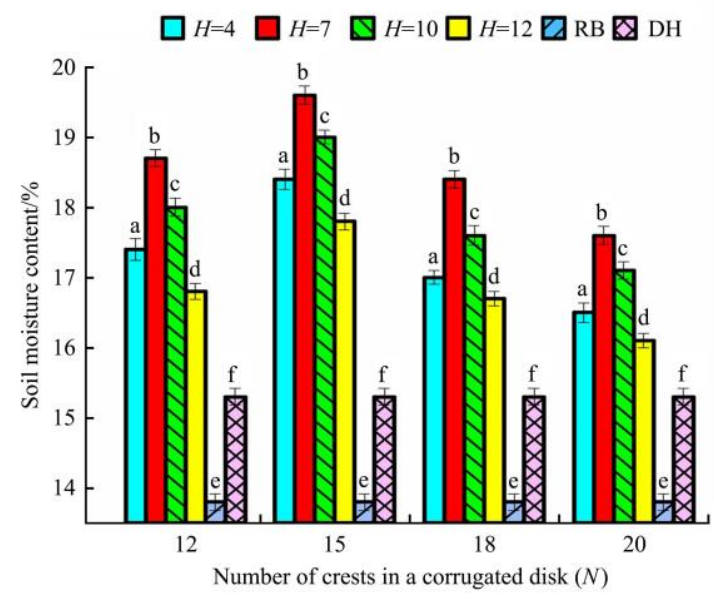

Note: Averages followed by different lowercase letters are significantly different according to LSD's multiple range test at the significance level of 0.05 . Error bars are standard deviation, the same as below.

Figure 7 Effects of bump height $(H)$ and number of crests in a corrugated disk $(N)$ on SMC
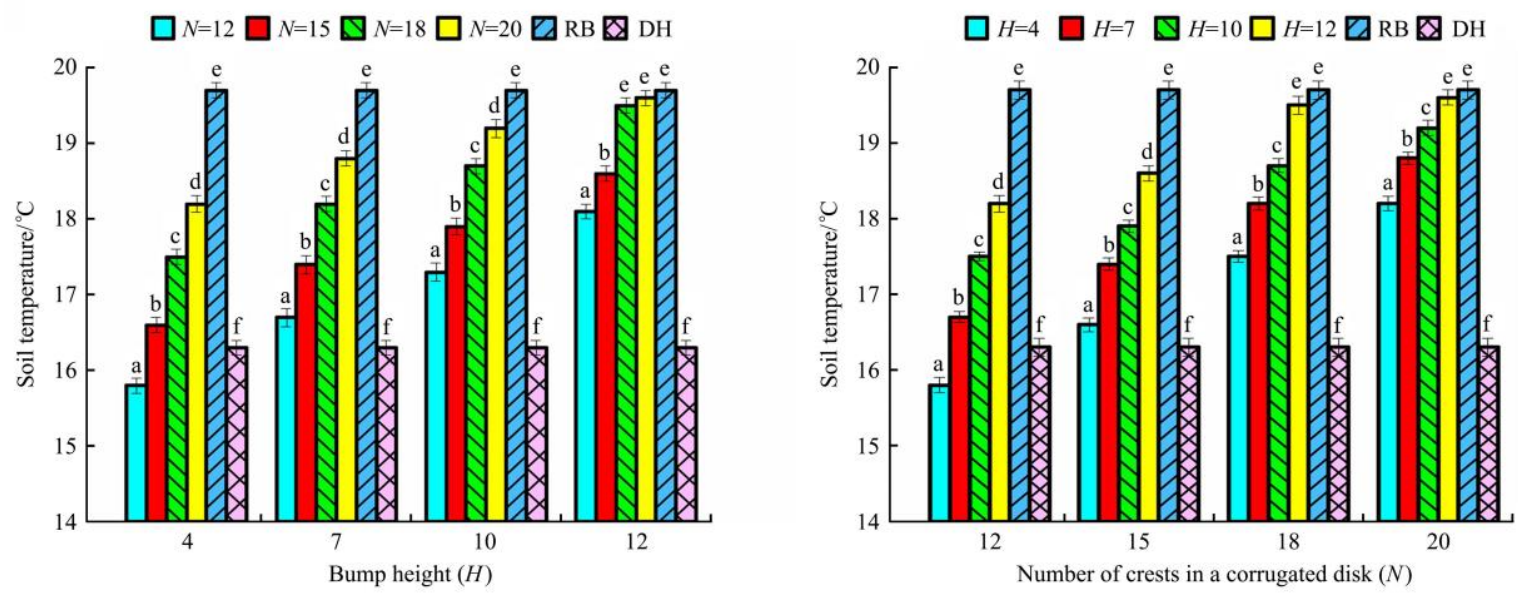

Figure 8 Effects of bump height $(H)$ and number of crests in a corrugated disk $(N)$ on ST 

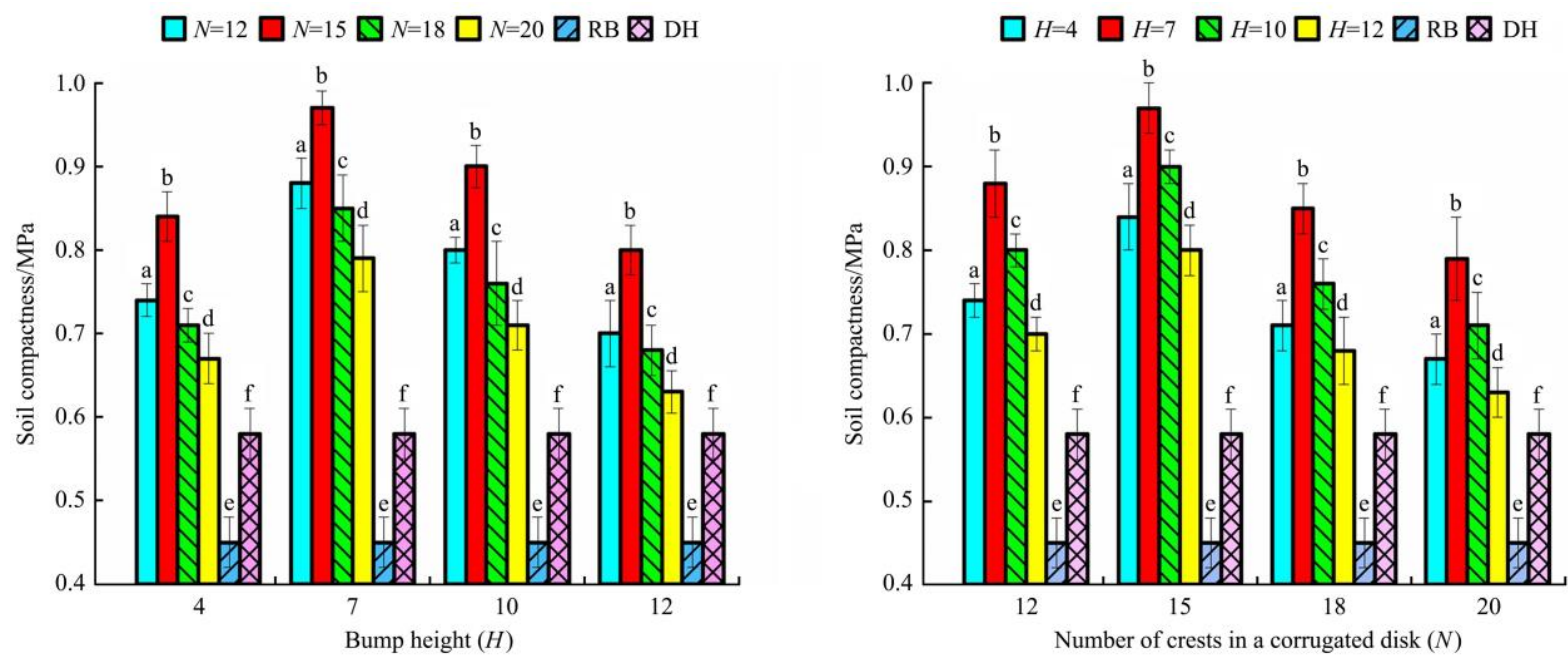

Figure 9 Effects of bump height $(H)$ and number of crests in a corrugated disk $(N)$ on SC
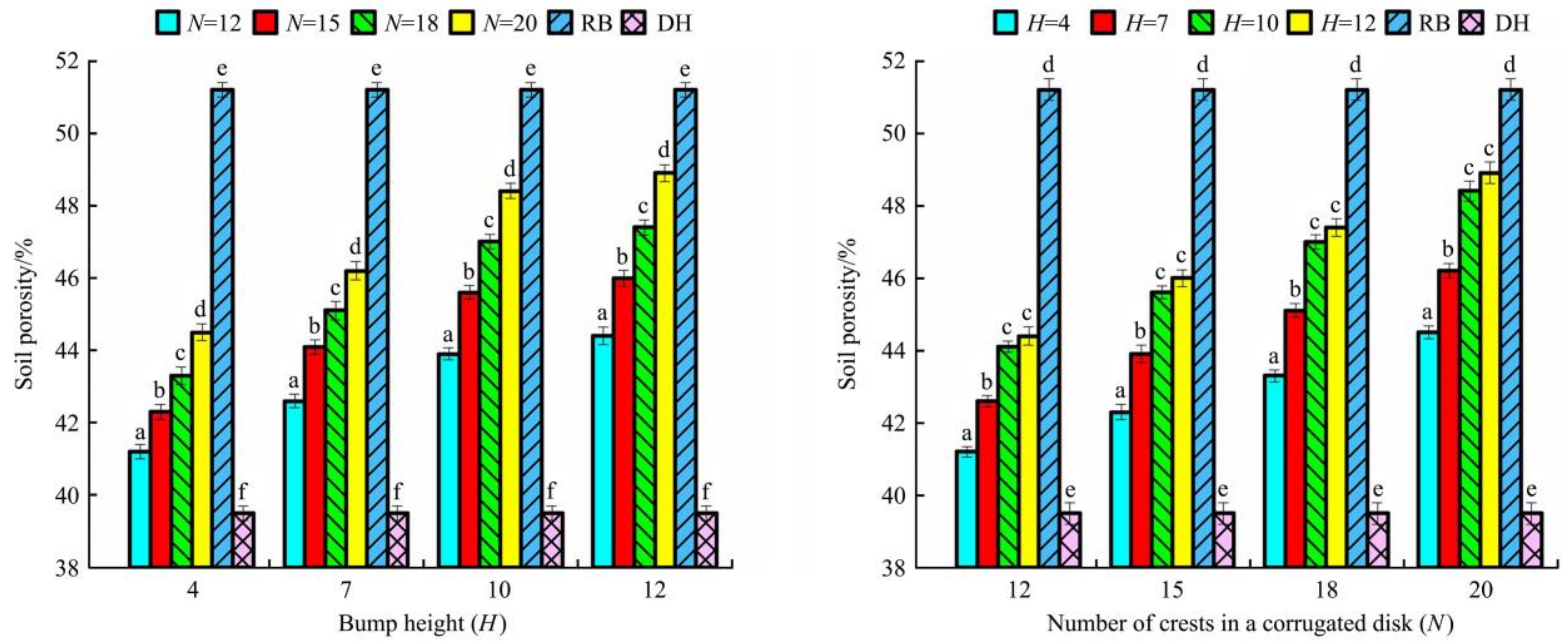

Figure 10 Effects of bump height $(H)$ and number of crests in a corrugated disk $(N)$ on SP
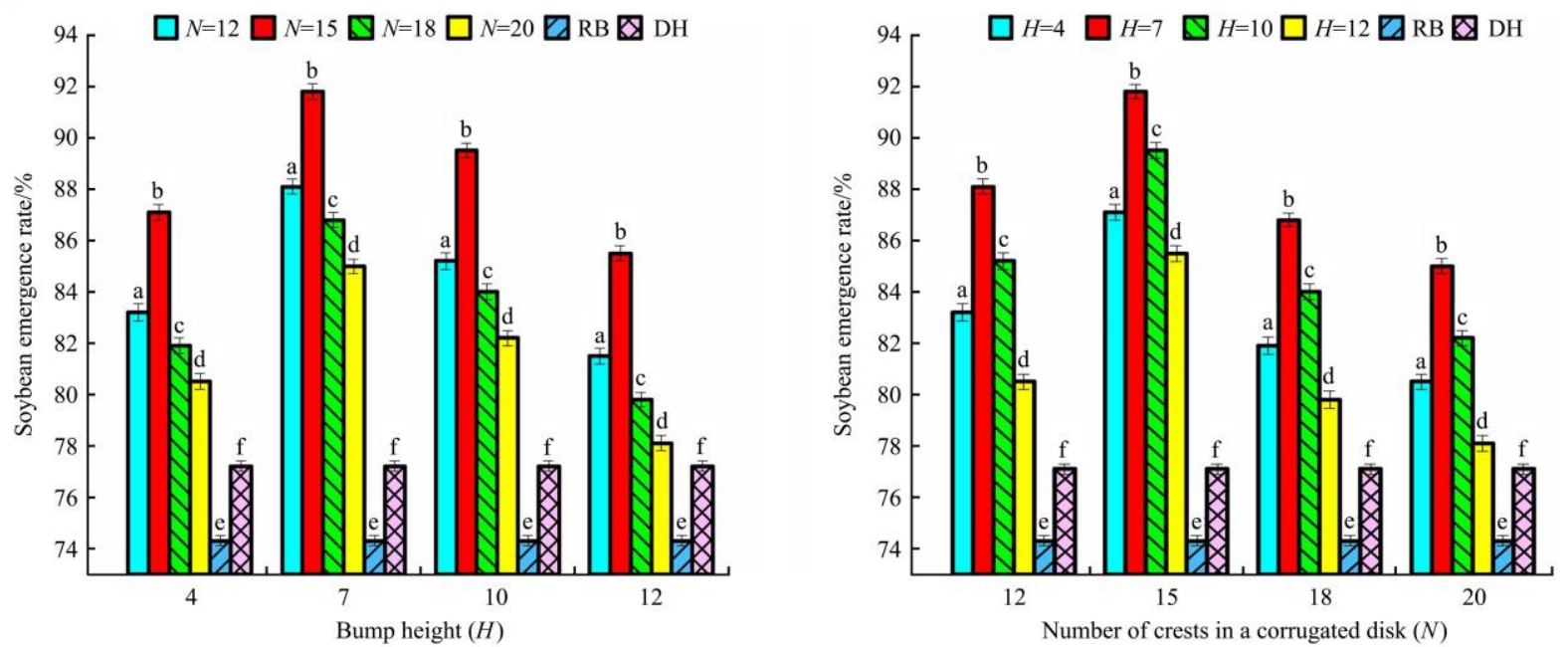

Figure 11 Effects of bump height $(H)$ and number of crests in a corrugated disk $(N)$ on SER

4.3 Effect of biomimetic earthworm dynamic soil looser on SE Rand optimization of design parameters

Figure 11 and AVONA results showed that the design parameters $(H$ and $N$ ) of biomimetic earthworm dynamic soil looser have significantly affected the SER. As shown in Figure 7, the analysis of LSD shows that SMC first increases and then decreases with $H$ and $N$. The SER of biomimetic earthworm dynamic soil looser is significantly higher than that of traditional tillage mechanism. When $H=7, N=15$, MER can reach $91.8 \%$, which is $23.5 \%$ and $18.9 \%$ higher than rotary blade and notched disc harrow, respectively. The results show that the effect of biomimetic earthworm dynamic soil looser on ST is basically the same as that of rotary tiller, but higher SMC can be obtained. When $H=12$ and $N=18$, there was no significant difference in ST between them, but the SMC difference was $2.7 \%$. Compared with the notched disc harrow, the biomimetic earthworm dynamic soil looser has significant advantages in improving the rate of heat absorption and reducing the rate of soil moisture loss. When $H=7$, 
$N=15$, the differences between ST and SMC were $4.3 \%$ and $2.1 \%$, respectively. In conclusion, compared with the traditional tillage mechanism, the biomimetic earthworm dynamic soil looser can enhance both ST and SMC, so a better SER can be obtained.

In order to obtain the optimal combination of design parameters of biomimetic earthworm dynamic soil looser, the experimental data were imported into MATLAB for regression analysis, and Equation (5) showed that the regression model between $N$ and SER was obtained under different $H$ conditions. Four models were tested for significance by GOF and $F$-test analysis. The $F$ values and correction coefficients $\left(R^{2}\right)$ of the four regression models are given in Table 3. $R^{2}$ is close to 1 , and the corresponding $p$-value of $F$-test is less than 0.05 , indicating that the regression model has high reliability and fitness. The regression curve is shown in Figure 12. It can be concluded that when $H=6.6$ and $N=15$, the theoretical emergence rate can reach $93.15 \%$, and the conclusion can provide guidance for soybean planting in cold and arid regions.

$$
\left[\begin{array}{l}
S E R_{N=12} \\
S E R_{N=15} \\
S E R_{N=18} \\
S E R_{N=20}
\end{array}\right]=\left[\begin{array}{cccc}
0.00753 & -0.5105 & 6.2703 & 63.2574 \\
0.05812 & -1.7765 & 15.9796 & 42.1857 \\
0.0554 & -1.6783 & 15.1625 & 45.6218 \\
0.08653 & -2.4463 & 21.0792 & 35.6942
\end{array}\right] \times\left[\begin{array}{l}
H^{3} \\
H^{2} \\
H \\
1
\end{array}\right]
$$

where, $H$ is the bump height, $\mathrm{mm}$; $S E R_{N=12}, S E R_{N=15}, S E R_{N=18}$, $S E R_{N=20}$ are the regression models between $H$ and SER when $N=12$, $15,18,20$, respectively.

Table 3 Results of $F$-test and goodness of fit on regression models

\begin{tabular}{ccccc}
\hline Model & $\operatorname{SER}_{N=12}$ & $\operatorname{SER}_{N=15}$ & $\operatorname{SER}_{N=182}$ & $\operatorname{SER}_{N=20}$ \\
\hline$R^{2}$ & 0.9839 & 0.9956 & 0.9988 & 0.9974 \\
$F$ & $51943.85^{* *}$ & $10995.574^{* *}$ & $25892.5^{* *}$ & $3012.425^{* *}$ \\
\hline
\end{tabular}

Note: The reliability and high fitness of the regression model were tested by goodness of fit (GOF) and $F$-test for 4 models. $\quad * *$ Significant at $1 \%$ probability $(p<0.05)$.

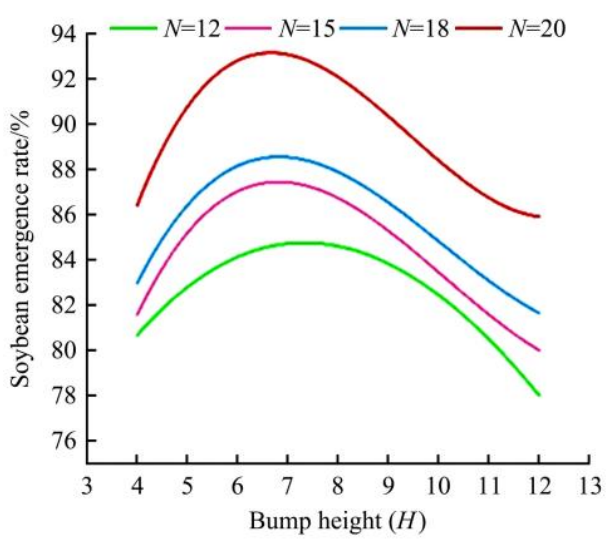

Figure 12 Regression curve between the bump height $(H)$ and

SER at different number of crests in a corrugated disk $(N)$

\subsection{Comparative verification test}

According to the optimal design parameters obtained above, the biomimetic earthworm dynamic soil opener was processed $(H=6.6, N=15)$ and compared with notched disc harrow and rotary blade. The test results are shown in Table 4. The results showed that the SMC rakes of earthworm dynamic soil release machine were $41.3 \%$ and $27.5 \%$ higher than rotary knife and notched disc harrow, ST was $7.97 \%$ higher than notched disc harrow, MER was $25.4 \%$ and $20.7 \%$ higher than rotary knife and notched disc harrow, respectively.
Table 4 Physical parameters of soil in test sites before tests

\begin{tabular}{lc}
\multicolumn{1}{c}{ Parameter } & Values \\
\hline Soil compactness/MPa & 0.95 \\
Soil temperature $/{ }^{\circ} \mathrm{C}$ & 17.6 \\
Soil moisture content $/ \%$ & 19.5 \\
Soil porosity/\% & 44.5 \\
Soybean emergence rate/\% & 93.2 \\
\hline
\end{tabular}

\section{Conclusions}

The biomimetic earthworm dynamic soil looser adopts the motion mode of earthworm in the soil, which can not only loosen the soil, but also realize the flexible compaction of the soil. The experimental results showed that compared with the traditional rotating forward tillage mechanism, this unique motion mode can effectively improve the soil compactness, thus reducing the soil moisture loss and increasing the absorption of groundwater. Therefore, compared with rotary blade and notched disc harrow, biomimetic earthworm dynamic soil looser has significant advantages in soil moisture content (SMC) lifting, which can be improved by $42.0 \%$ and $24.5 \%$ respectively (when the bump height of the biomimetic earthworm circular muscle mechanism $H$ $=7$, and the number of crests in a corrugated disk $N=15$ ). By simulating the motion path of earthworms, the biomimetic earthworm dynamic soil looser can construct a large number of penetrating pore structures. The experimental results show that the pore structure can obtain higher soil temperature (ST) under lower soil porosity (SP) conditions. For example, when $H=12, N$ $=18$ or 20, SP after earthworm dynamic soil looser operation was significantly lower than that of rotary blade, but no significant difference was obtained in ST. The above results indicate that compared with the traditional rotating forward tillage mechanism, the pore structure constructed by the biomimetic earthworm dynamic soil looser has a better heat absorption efficiency, so that it can effectively restrain the soil moisture loss under the premise of accelerating the soil heat absorption rate. Therefore, compared with the notched disc harrow, earthworm dynamic soil looser has a significant advantage in improving ST, which can increase by $20.24 \%$ (when $H=12, N=20$ ). Compared with rotary blade, earthworm dynamic soil looser could improve SMC19.6\% without significant difference in ST (when $H=12, N=18$ ).

In conclusion, by highly reducing the motion mode and path of earthworms, earthworm dynamic soil looser can obtain a soil structure with a compact interior and a large number of penetrating pores. The results showed that the soil structure could significantly improve the soybean emergence rate in cold and arid regions. According to the mathematical relationship model between design parameters and soybean emergence rate, the optimal design parameter combination of biomimetic earthworm dynamic soil looser is $H=6.6 \mathrm{~mm}, N=12$. Compared with notched disc harrow and rotary tiller, earthworm dynamic soil loosening device could increase the soybean emergence rate by $25.4 \%$ and $20.7 \%$, respectively.

\section{Acknowledgements}

The authors acknowledge that the research was financially supported by the Natural Science Foundation of China (Grant No. 52075215), National Key Research and Development Program of China (Grant No. 2017YFD0700701), Science and Technology Development Plan Project of Jilin Province (Grant No. 
$20190301023 \mathrm{NY}$ and 20190701055GH and 20200404008YY), and China Postdoctoral Science Foundation (Grant No. 2020M67085).

\section{[References]}

[1] Jumrani K, Bhatia V S. Interactive effect of temperature and water stress on physiological and biochemical processes in soybean. Physiology Molecular Biology of Plants, 2019; 25: 667-681.

[2] Piccoli I, Lazzaro B, Furlan L, Berti A, Morari F. Examining crop root apparatus traits in a maize-soybean-winter wheat rotation under conservation agriculture management. European Journal of Agronomy, 2021; 122: 126171. doi: 10.1016/j.eja.2020.126171.

[3] Li Q L, Wang M, Fu Q, Li T X, Liu D, Hou R J, et al. Short-term influence of biochar on soil temperature, liquid moisture content and soybean growth in a seasonal frozen soil area. Journal of Environmental Management, 2020; 266: 110609. doi: 10.1016/j.jenvman.2020.110609.

[4] Shiferaw H, Gebremedhin A, Solomon N, Taye G, Zenebe A. Comparative study on spatial variability of topsoil moisture content and carbon stocks as influenced by land use and soil and water conservation structures in the semi-arid Ethiopian highlands. Physical Geography, 2020; 41(5): 389-406

[5] Qaio J Y, Zhang D, Zhang H B, Zhang B, Chen H T, Chen L P, et al. Effects of soil compaction by various tractors on soil penetration resistance and soybean yields. Transactions of the CSAE, 2019; 35(21): 26-33. (in Chinese)

[6] Salinas J R, Matocha J E, Hons F M. Long-term tillage and nitrogen fertilization effects on soil properties of an Alfisol under dry land corn/cotton production. Soil and Tillage Research, 1997; 42(1): 79-93.

[7] Zhu R X, Li C X, Cheng Y, Yan X L, Li J. Working performance of passive disc coulter. Transactions of the CSAE, 2014; 30(18): 47-54. (in Chinese).

[8] Gubiani P I, Reichert D J, Reichert J M. Critical values of soil bulk density evaluated by boundary conditions. Ciência Rural, 2014; 44(6): 994-1000. (in Portuguese)

[9] Hua S, Chen Y, Liang L T, Ren T S. Studying soil pore structure by using image filtering technology based on partial differential equation model. Transactions of the CSAE, 2014; 30(3): 78-85. (in Chinese).

[10] Zhang J L, Tanveer S K, Wen X X, Chen Y X, Gao M B. Soil respiration and its affecting factors in dry-land maize field under different tillage systems. Transactions of the CSAE, 2012; 28(18): 192-199. (in Chinese).

[11] Kuncoro P H, Koga K, Satta N, Muto Y. A study on the effect of compaction on transport properties of soil gas and water. II: Soil pore structure indices. Soil Till Res, 2014; 143(12): 180-187.

[12] Ahmet C, Sefa A, Thomas R. Strip tillage width effects on sunflower seed emergence and yield. Soil Till Res, 2013; 131(5): 20-27.

[13] Lin H H, Xie Y, Liu G, Zhai J R, Li S. Soybean and maize simulation under different degrees of soil erosion. Field Crop Res, 2019; 230: 1-10.

[14] Alphei J, Bonkowski M, Scheu M. Application of the selective inhibition method to determine bacterial: fungal ratios in three beechwood soils rich in carbon - Optimization of inhibitor concentrations. Biology and Fertility of Soils, 1995; 19: 173-176.

[15] Fidantemiz Y F, Jia X H, Daigh A L M, Hatterman-Valenti H, Steele D D, Niaghi A R, et al. Effect of water table depth on soybean water use, growth, and yield parameters. Water-Sui, 2019; 11(5): 931. doi:
$10.3390 / \mathrm{w} 11050931$

[16] Li W F, Zhang X P, Liang A Z, Shen Y, Fang H J. Impacts of no-tillage on earthworm and soil bulk density in black soil in northeast China. System Sciences and Comprehensive Studies in Agriculture, 2007; 23(4): 489-493. (in Chinese)

[17] Bardgett R D, Cook R. Functional aspects of soil animal diversity in agricultural grasslands. Applied Soil Ecology, 1998; 10(3): 263-276.

[18] Hao G Y, Huang M S, Xu Y T. Earthworms and their application to eco-environmental protection. Research of Environmental Sciences, 2004 17(3): 75-77. (in Chinese)

[19] Liu G M, Li J Q, Zou M, Li Y W, Tian X M. Feature and the characteristic of sliding resistance reduction of the earthworm's non-smooth surface. Transactions of the CSAE, 2008; 24(12): 62-65. (in Chinese).

[20] Neve D, Hofman G. Influence of soil compaction on carbon and nitrogen mineralization of soil organic matter and crop residues. Biology and Fertility of Soils, 2000; 30: 544-549.

[21] Institute of Mechanical Industry Information. Mechanical design handbook. Beijing: Chemical Industry Press, 2017; pp.507-510.

[22] Zhao J L, Lu Y, Tian H L, Jia H L, Guo M Z. Effects of straw returning and residue cleaner on the soil moisture content, soil temperature, and maize emergence rate in China's three major maize producing areas. Sustainability-Basel, 2019; 11: 5796. doi: 10.3390/su1120579.

[23] China Academy of Agricultural Mechanization Science. Agricultura machinery design manual. Beijing: China Agricultural Science and Technology Press, 2007; pp.378-380.

[24] Jia H L, Zheng J, Zhao J L, Guo M Z, Zhuang J, Wang Z H. Design and parameter optimization of earthworm-like multi-function opener. Transactions of the CSAE, 2018; 34(12): 62-71. (in Chinese).

[25] Sun T W, Xu L H, Wang H B, Sui B. Effects of different tillage managements on black soil physicochemical properties and corn yield. Journal of Jilin Agricultural University, 2020; 42(4): 421-426. (in Chinese)

[26] Li S D, Wang F H, Si J S, Kong L A, Liu J J, Feng B, et al. Effect of different farming methods on soil microbial biomass and soil fertility. Ecology and Environmental Sciences, 2009; 18(5): 1961-1964. (in Chinese)

[27] Dürr C, Aubertot J N, Richard G, Dubrulle P, Duval Y, Boiffin J. A model for simulation of plant emergence predicting the effects of soil tillage and sowing operations. Soil Sci Soc Am J, 2001; 65(2): 414-423.

[28] Feng X, Hao Y, Latifmanesh H, Rattan Lal, Cao T H. Effects of subsoiling tillage on soil properties, maize root distribution, and grain yield on mollisols of Northeastern China. Agronomy Journal, 2018; 110(4): 1607-1615.

[29] Cong C, Wang T S, Yue L K Zhou X, Li Y M, Yao S H. Amendment effect of subsoiling with organic materials application on soil physical properties of slope cropland in Mollisol region. Soils and Fertilizers Sciences in China. Available: https://kns.cnki.net/kcms/detail/ 11.5498.S.20201111.1024.006.html. Accessed on [2020-11-11]. (in Chinese)

[30] Mosaddeghi M R, Hajabbasi M A, Hemmat A, Afyuni M. Soil compactibility as affected by soil moisture content and farmyard manure in central Iran. Soil and Tillage Research, 2000; 55(1-2): 87-97.

[31] Kuncoro P H, Koga K, Satta N, Muto Y. A study on the effect of compaction on transport properties of soil gas and water I: Relative gas diffusivity, air permeability, and saturated hydraulic conductivity. Soil and Tillage Research, 2014; 143(12): 172-179. 